\title{
EDITORIAL
}

\section{Space industrialization}

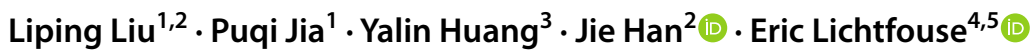

Published online: 21 February 2022

(c) The Author(s), under exclusive licence to Springer Nature Switzerland AG 2022

\section{Humans are messy, and not just here on Earth.}

Bohannon, 2015

On November 15, 2021, a Russian anti-satellite test produced more than 1,500 pieces of orbital debris that threatened the crew of the international space station. The crew members sheltered in capsules in case they had to evacuate (Blinken 2021). So far, more than 8000 tons of orbital debris have been generated from human space missions (NASA 2020). Moreover, the dawn of 'space tourism', a term popularized by recent space missions, marks an acceleration of the era of space industrialization (Spacex24 2021). While recent reports have focused on space collisions induced by space debris, there is actually little discussion on the effect of space industrialization on the earth's environment (NASA 2021a; MSN 2021).

Here, we review the impacts of space debris on earth's environment. About 23,000 objects larger than a softball, more than about $10 \mathrm{~cm}$, amounting to a total weight of 8000 tons, are actually orbiting the earth at speeds up to 17,500 miles per hour (NASA 2020, 2021b). By reflecting and scattering sunlight, man-made space objects and debris have increased the night sky brightness on earth by

Puqi Jia

jpq@1zu.edu.cn

$\bowtie$ Jie Han

jiehan@xjtu.edu.cn

1 Department of Environmental Science and Engineering, College of Earth and Environmental Sciences, Lanzhou University, Lanzhou 730000, People's Republic of China

2 Institute of Global Environmental Change, School of Human Settlements and Civil Engineering, Xi' an Jiaotong University, Xi'an 710049, People's Republic of China

3 College of Environmental Science and Engineering, Fujian Normal University, Fuzhou 350007, People's Republic of China

4 Aix-Marseille University, CNRS, IRD, INRAE, CEREGE, 13100 Aix-en-Provence, France

5 State Key Laboratory of Multiphase Flow in Power Engineering, Xi' an Jiaotong University, Xi' an 710049, Shaanxi, People's Republic of China approximately $10 \%$ of the luminance of a typical natural night sky (Kocifaj et al. 2021). Upon burning, some space debris consumes ozone and release carbon dioxide, which may-unlike in the lower atmosphere-induce cooling and contraction of the thermosphere due to increased heat shedding via infrared radiation (Staughton 2020; Derrick 2010; Laštovička et al. 2006). Rocket and plane propellants are likely to pollute the earth's atmosphere and deplete the stratospheric ozone (Dallas et al. 2020). The falloff of nuclearpowered engines and parts may cause large radioactive pollution (Levi 2007). As a consequence, mitigation guidelines for orbital debris have been proposed by some countries, though with limited success to date (NASA 2011).

Humanity has continuously made progress in space expeditions. 2021 has been a particularly busy year for the exploration of the Red Planet with the perseverance rover program, the United Arab Emirates mars mission, and China's Zhurong rover (NASA 2021c; UAESA 2021; CNSA 2021). As humorously put by John Bohannon, humans are messy, and not just here on Earth, and thus space waste has become the common human 'footprint' of space missions. Space debris, also known as space junk or orbital debris, refer to all kinds of abandoned wastes left in cosmic space, including discarded or out of control spacecrafts, fuels, parts, and wreckages (Fig. 1, Chepkemoi 2019; NASA 2021b). Since humans started launching artificial objects into space in the 1950s, space debris have continuously spawned and accumulated (Lawler 2011; Staughton 2020). So far, over 5250 space launches have been successfully completed, producing an orbital wasteyard composed of approximately 500,000 objects of a marble size or larger, more than $1 \mathrm{~cm}$, of which 23,000 are larger than a softball, about $10 \mathrm{~cm}$, with a total mass exceeding 8000 tons (NASA 2020; ESA 2020; NG 2019; Witze 2018). In addition to disused satellites, the population of smaller space debris objects is increasing at an annual rate of approximately 5\% (Dekorsy et al. 2017).

There is actually no realistic method to clean up space debris, despite recent attempts (Forshawa et al. 2020; Pultarova 2018). This aggravating issue for outer space safety has raised concerns from the United Nations, the 


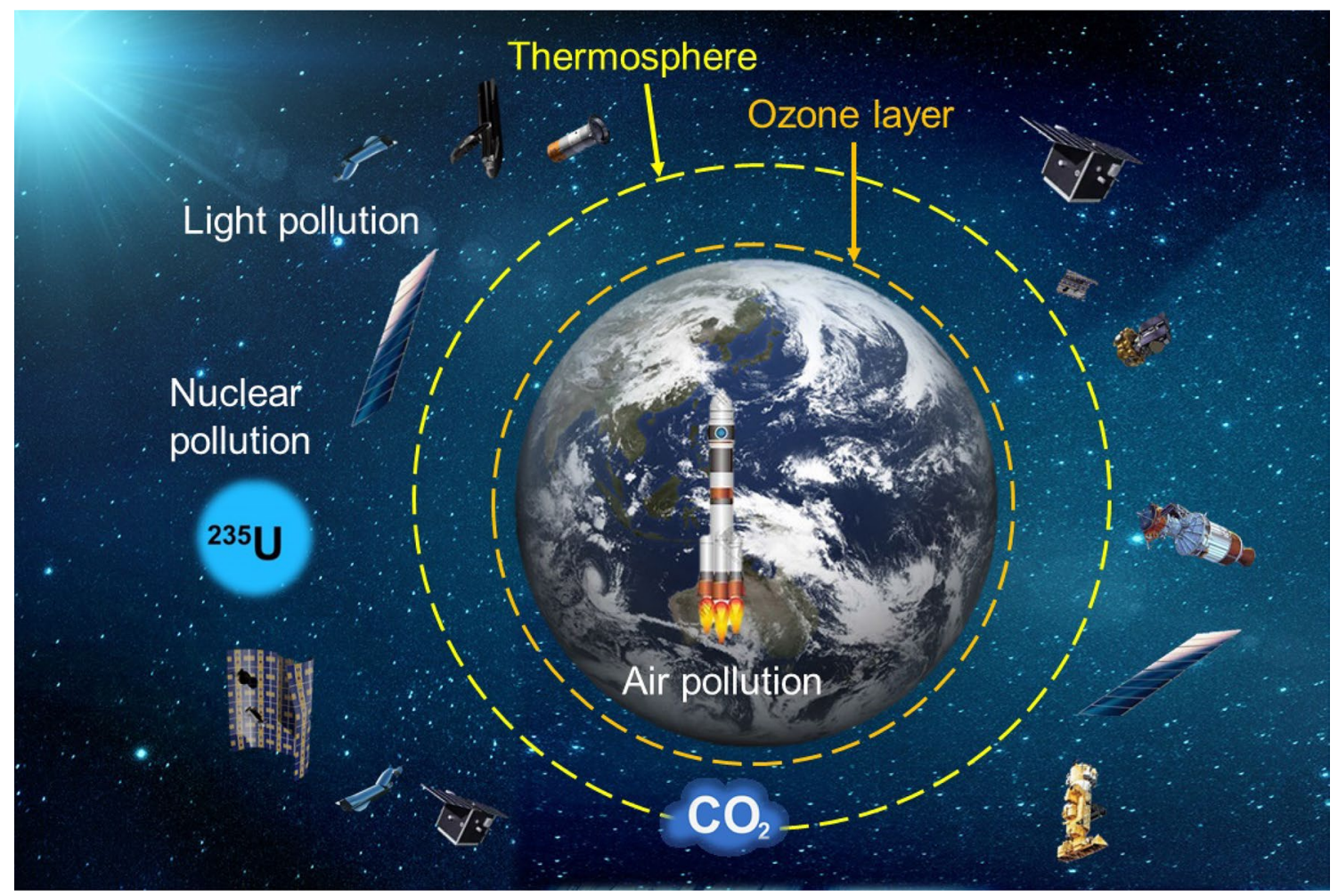

Fig. 1 Man-made objects, including space debris, have increased the night sky brightness on earth by approximately $10 \%$ of the luminance of a typical natural night sky. Zenith luminance of this additional light pollution source reached about $20 \mu \mathrm{cd} \mathrm{m} \mathrm{m}^{-2}$ by reflecting and scattering sunlight, resulting in the disappearance of locations on earth suitable for astronomical observatories. Some space debris consume ozone and release carbon dioxide or other compounds when

European Commission, and countries actively engaging in space exploration missions including the USA, China, Japan, and Switzerland (Crowther 2002; Schaper 1999; Clery 2012, 2020; CNSA 2016b; Loomis 2015; Normile 2016). Nonetheless, previous debates have focused almost exclusively on space collision between debris and satellites or-worse-inhabited space stations (NASA 2021a; MSN 2021).

There are approximately 23,000 pieces of debris larger than a softball orbiting the earth, traveling at speeds up to 17,500 miles per hour, circa $7.8 \mathrm{~km}$ per second, which is fast enough for one small piece of orbital debris to catastrophically damage a satellite or a spacecraft (ESA 2020; NASA 2021b) (Fig. 2). In 1996, a French satellite was hit and severely damaged by the debris shed from a French rocket that exploded a decade earlier (NASA 2021b). The risk of collision induced by space debris was vividly depicted in the 2013 movie Gravity, which thus raised public attention on space debris as a major safety threat for astronauts working in international space stations. In the meantime, there have only been anecdotal discussions on the potential debris return to the thermosphere and burn, which may lead to the cooling and shrinkage of the thermosphere due to excessive infrared radiation. Solid or liquid propellants used in rocket launching pollute the atmosphere on earth. Although infrequent, radioactive debris have been left in earth's atmosphere from nuclear-powered components in space objects launched decades ago. The drawing is not to any particular scale

impact of space debris on the earth's environment and ecosystems (Graham 2021; Sokol 2021; Staughton 2020). Here we review evidence and scholarly opinions on the impact of space debris on the ecosystem on earth, covering light pollution, atmospheric pollution, spread of radioactive wastes, and other impacts.

\section{Light pollution}

Places available for viewing stars without light pollution from orbital debris and other man-made objects are vanishing on earth. It is estimated that the night sky brightness on earth has increased by about $10 \%$ due to sunlight reflected and scattered by objects and debris orbiting earth (Kocifaj et al. 2021). This calculation is based on the number and size distribution of space objects in the mid-1990s, extrapolating their numbers since then, and estimating how reflective these objects would be on average (Kocifaj et al. 2021; Sokol 2021). Preliminary estimates suggest that this additional source of light pollution increases the zenith brightness to 


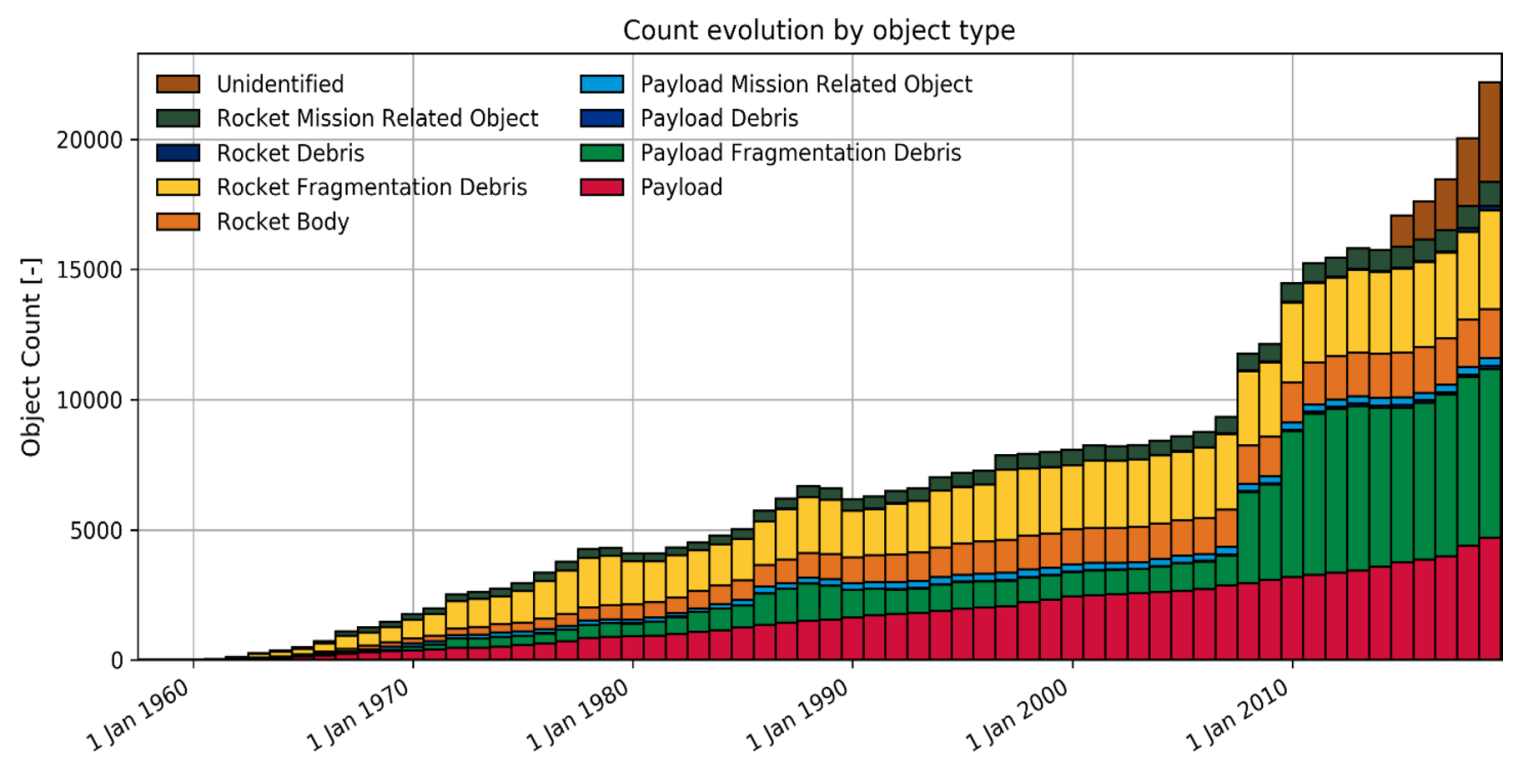

Fig. 2 Since the 1950s, the number of space debris has been increasing at an average rate of approximately 5\% per year. Payload fragmentation debris accounted for the largest category of space debris emerged in the past decade (2010-2019). Adapted from ESA (2020)

about $20 \mu \mathrm{cd} \mathrm{m}{ }^{-2}$, the threshold for light pollution obstructing astronomical observatories (Kocifaj et al. 2021). New astronomical observatories can be established only if the proportion of light pollution to the natural sky glow does not exceed 10\% (Sokol 2021). Most orbital debris reside within $2000 \mathrm{~km}$ of Earth's surface, with the highest concentrations found near 800-850 km (NASA 2011). While some falling space debris can fully combust after re-entering earth's atmosphere, some aerospace materials are incompletely burnt due to their high melting points, generating fine particulates, paint flakes, and solid propellant particles when colliding with each other or due to frictions with the atmosphere when moving at high velocities (NASA 2010; Crowther 2002; ESA 2020). Once released into the atmosphere, this particulate matter scatters light, causing light pollution (Graham 2021; Kamenev et al. 1997; Kocifaj et al. 2021; Sokol 2021; Staughton 2020).

\section{Atmospheric pollution and climate impact}

Similarly as the ozone hole that has been induced by emissions of chlorofluorocarbon refrigerants, changes in the upper atmosphere could have long-term impact on the environment and climate on earth (https://en.wikipedia.org/ wiki/Ozone_depletion, Laštovička et al. 2006). In 2010, the NASA warned that the upper layer of the earth's atmosphere has shrunk abruptly in the last four decades, with abnormal low densities that were about $30 \%$ lower than previous contractions on record since 1967 (Derrick 2010). Studies showed that, unlike in the lower atmosphere, carbon dioxide
$\left(\mathrm{CO}_{2}\right)$ acts as a coolant in the upper atmosphere, constantly releasing energy into space. There are known sources of carbon dioxide from space missions, namely, emissions from fuel combustion during rocket flights and the combustion of space debris after re-enter earth's atmosphere. About 80 tons of orbital debris re-enter earth's atmosphere every year, and most of these debris burn up in the thermosphere (Lemaitre 2019; Staughton 2020). Some metallic and polymeric orbiting debris undergo chemical reactions when burning through the atmosphere, depleting ozone and generating carbon and nitrogen oxides (Physics Today 2009; Staughton 2020). Also, emissions from space mission launches cause significant atmospheric pollution, and the combustions of solid rocket motor fuels and liquid propellants through the upper atmosphere have raised concerns on the loss of stratospheric ozone (Dallas et al. 2020).

\section{Radioactive wastes}

Potential radioactive pollution falling from abandoned space objects to earth surface is an overlooked topic. At least eight radioisotope thermoelectric generators, 13 nuclear reactor fuel cores, and 32 nuclear reactors were circling the earth in orbit below $1700 \mathrm{~km}$ in 2005 (WISE 2005). The USA and the former Soviet Union had about one ton of uranium 235 and other nuclear fuels in their nuclear reactors orbiting in space around the earth (Bunn and Holdren 1997; WISE 2005). Two nuclear-powered reconnaissance satellites launched by the former Soviet Union had indeed brought radioactive pollution to the earth surface. In the 
first incident, a multitude of radioactive debris from Cosmos 954 fell into earth's atmosphere and spread over large areas in Canada in 1978. Here, about $30 \mathrm{~kg}$ of enriched uranium, reactor wreckages, and radioactive debris spilled on a ground path stretching over a distance of 600 kilometers, causing serious radioactive pollution (SL 1981; Rich 1978; DiaNuke 2020).

Five years later, the nuclear reactor core of Cosmos 1402 fell into the South Atlantic Ocean (Leifer et al. 1987; Rich 1983). In order to track and ascertain the whereabouts of the reactor core, a series of aerosol samples were collected about a year later at altitudes between 27 and $36 \mathrm{~km}$ using high-altitude balloons. The results showed that ${ }^{235} U$ concentrations were higher than background levels by $53 \pm 20 \%$ at an altitude of $36 \mathrm{~km}$, and the total excess of ${ }^{235} \mathrm{U}$ was estimated to be $44 \pm 15 \mathrm{~kg}$ in the stratosphere (Paddy 1983; Leifer et al. 1987). Given the long half-lives of radioactive isotopes, it is likely that space nuclear fuels and radioactive materials will eventually spread into earth's atmosphere, causing radioactive pollution for many years after the life of the space object ends (Levi 2007). Further, the unrestrained nature of space debris means that these radioactive pollutants may fall into populated areas on earth at unpredictable timing (CNBC 2021).

\section{1 , the dawn of space tourism}

When the Russian astronaut Yuri Gagarin became the first human to journey into the outer space, no one would think that ordinary people could, one day, venture into space for leisure (Space 2021). Yet, a series of recent events have marked the dawn of commercial space travel, or 'space tourism', aided by the remarkable advancements in astronautics and engineering. In addition to professional astronauts, untrained earth citizens have traveled into space since the beginning of the new millennium when Dennis Tito, an American businessman, became the world's first orbiting space tourist in 2001 (Wall 2011). The Russian Space Agency put seven paying customers in space between 2001 and 2008 (Messier 2021).

The race to space accelerated rapidly in 2021 . Virgin Galactic, a US-based space flight company, demonstrated the readiness of its air-launched spaceplane for ticket-paying passengers by completing its first suborbital test flight with VSS Unity, a rocket-powered spaceplane (Malik 2021). On July 11, 2021, VSS Unity successfully flew a group of space tourists to the edge of space using a hybrid propellant comprised of hydroxyl-terminated polybutadiene, a solid carbonbased fuel, and nitrous oxide, a liquid oxidant (VG 2021). The combustion of these fuels produces greenhouse gases and air pollutants, which can last at least two to three years in the atmosphere (Marais 2021).
Nine days later, four citizens including Jeffrey Bezos, the founder of Amazon, took the New Shepard rocket launched by Blue Origin, a private space tourism company, for a short space trip by passing the Kármán Line, the internationally recognized boundary of earth's atmosphere and the outer space, and safely returned (BO 2021). Not to be outdone, SpaceX announced its schedule to offer 4-5 days of orbital travel using its Falcon series of reusable rockets to propel its Crew Dragon capsule into the orbit, using liquid kerosene and liquid oxygen (Marais 2021). On September 18, 2021, the Dragon and the Inspiration4 originated from SpaceX was successfully launched by a Falcon 9 rocket and finished the first commercial manned space mission by sending four citizens into space for a three-day space tour and safely returned off the coast of Florida, as part of a charitable effort on behalf of St. Jude Children's Research Hospital in Memphis, Tennessee in the USA (Stein 2021). This was the first time in history that humans ever completed an orbital mission without professional astronauts, reaching another milestone in commercializing space travel (Stein 2021).

These highly publicized events of individuals traveling to space for leisure and the significantly lowered costs of space flight have sparked worldwide interest in the possibility of mass space travel by earth citizens (Reeve 2021). Industrial insights suggest that space tourism could be worth more than three billion dollars by 2030 (Reeve 2021; Sheetz 2019). However, criticism has also been raised with respect to the environmental impact of those extremely costly and energyintensive leisure activities (Bohannon 2015). Sitting at the dawn of space tourism, it is important to establish international conventions and regulations and invest in new technological developments to minimize anthropogenic debris and pollutants generated by those activities (Sheetz 2019).

\section{Space cleaning}

To date, NASA, the European Space Agency, and China have issued mitigation guidelines for orbital debris (NASA 2011). In March 2020, the United States Space Force proposed the use of Space Fence, a radar surveillance system for tracking and measuring space objects, including microsatellites and orbital debris, primarily in low-earth orbit. The system could identify 20,000 objects a day and track 200 near-Earth debris simultaneously (Mizokami 2020; LM 2020). Earlier, the ClearSpace-1 mission, the space harpoon, and other initiatives were proposed by the European Space Agency to clean up space junk (Pultarova 2018; ESA 2019). Here, the first objective was to capture space debris, then to push them into earth's atmosphere for incineration (Pultarova 2018). The European Space Agency also planned to send a self-destructing robot into orbit in 2025 , which is designed to function as a space vacuum cleaner (NPR 2019). 


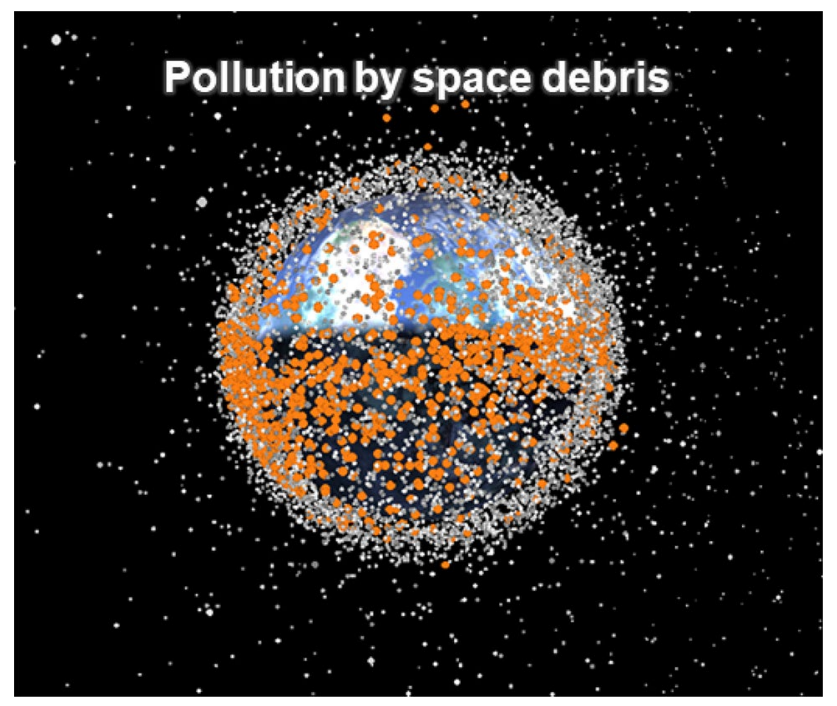

Fig. 3 Snapshot of the data-driven animation of the debris generated from past human space missions (1957-2015) and abandoned in earth orbits and beyond. It is estimated that, as of 2015, there were about 20,000 known pieces of space debris bigger than an apple-traveling at 17,000 miles per hour or faster-making earth orbits and the outer space a very cluttered place. See the full interactive 3D animation at the website maintained by the Royal Institution of the UK (https:// www.rigb.org/docs/debris/). Credit: Dr. Stuart Grey, University College London, 2015

As one of the signatories of the Outer Space Treaty, the Chinese government has committed to reduce space debris and invest in cleanup programs (CNSA 2016a). In 2016, China launched the AoLong-1 Roaming Dragon satellite, a space-debris automatic cleaning aircraft that was designed to grab space junk orbiting in the space and throw it back into earth's atmosphere for burning, but the results are presently unavailable (Forshawa et al. 2020). Some researchers proposed using powerful lasers to clean up old satellites and other orbital debris (Wen et al. 2018). These impressive proposals, however, faced significant technological or financial obstacles. It is also much better to control the source of debris generation than to clean up the debris once they are left in space. So far, recyclable rockets are the only proven option of reducing debris generation. Designed and manufactured by SpaceX in 2010, the Falcon 9 is a reusable twostage rocket designed to transport people and payloads into the earth orbit and beyond. In the long term, using reusable rockets and spacecraft with clean hydrogen-based fuels will fundamentally address the problem of space debris generation in future space missions (Spacex24 2020).

Empowered by new technological and engineering advancements, humans will continue to explore the universe in the coming decades, and perhaps in a more aggressive and frequent manner. Orbital debris are persistent and difficult to remove, thus creating stock effects (Fig. 3). Launch rates of space objects reached around 110 per year in 2020, with annual breakups continuing to occur at average rates of 10-11 per year (ESA 2020). With the current enthusiasm in space exploration and more countries willing to join the race in a near future, the number of debris objects in space is likely to increase (ESA 2015, 2020). As a consequence, more fuel rockets, satellites, spacecraft, and inevitably, debris will be abandoned in orbitals and outer space. There is already ample evidence on their impact on earth's environment. The rapidly increasing quantities of debris also pose a prominent threat to the safety of astronauts and other people entering or living in space. It is time for us to formulate a pragmatic, environmentally responsible response to the legacies of past and future human space missions. Along with astronautical engineers, environmental scientists and engineers have an essential role to take in addressing these longstanding issues.

With the intensifying activities in space missions and tourism, it can be anticipated that more space flights will take place in a near future, with more rockets, satellites, spacecraft, and inevitably debris left in the orbital space upon earth, casting an increasing impact with potential threats to earth's ecosystems. We call on global leaders and researchers to take actions to mitigate the unintended impact of space debris on earth. Meanwhile, new technology and engineering advancements such as reusable and clean energy-fueled rockets can drastically reduce orbital debris generated from space missions.

Acknowledgements This work was funded by the Young Talent Support Plan of Xi' an Jiaotong University and the Research Startup Fund for Young Research Fellows of Lanzhou University (No. 504000-561119211).

\section{Declarations}

Conflict of interest The authors declare that they have no conflict of interest in this work.

\section{References}

Blinken AJ (2021) Russia conducts destructive anti-satellite missile test. US department state. https://www.state.gov/russia-conductsdestructive-anti-satellite-missile-test/

Blue Origin (BO) (2021) Blue Origin safely launches four commercial astronauts to space and back. https://www.blueorigin.com/newsarchive/first-human-flight-updates. Accessed 25 Dec 2021

Bohannon J (2015) Video: watch 60 years of space junk accumulate in 1 minute. Science. https://doi.org/10.1126/science.aae0154

Bunn M, Holdren JP (1997) Managing military uranium and plutonium in the United States and the Former Soviet Union. Annu Rev Energy Environ 22:403-486. https://doi.org/10.1146/annur ev.energy.22.1.403

Chepkemoi J (2019) What is space junk? Space junk definition. www. worldatlas.com/articles/what-is-space-junk.html. Accessed 25 Dec 2021 
China National Space Administration (CNSA) (2016a) China's space activities in 2016a. http://www.cnsa.gov.cn/english/n6465652/ n6465653/c6768527/content.html. Accessed 25 Dec 2021

China National Space Administration (CNSA) (2016b) The first ChinaUS space debris experts' seminar has been held in Washington. http://www.cnsa.gov.cn/n6758823/n6758840/c6772734/content. html. Accessed 25 Dec 2021

China National Space Administration (CNSA) (2021) Probe makes historic landing on Mars. http://www.cnsa.gov.cn/english/n6465 652/n6465653/c6812005/content.html. Accessed 25 Dec 2021

Clery D (2012) Swiss want to build a satellite that removes space litter. Science. https://www.sciencemag.org/news/2012/02/swiss-wantbuild-satellite-removes-space-litter. Accessed 25 Dec 2021

Clery D (2020) Europe plans space claw to capture orbiting junk. Science. https://doi.org/10.1126/science.abf9608

Consumer News and Business Channel (CNBC) (2021) China says its rocket debris landed in the Indian Ocean. https://www.cnbc.com/ 2021/05/09/china-says-rocket-debris-landed-in-indian-oceanwest-of-maldives.html. Accessed 25 Dec 2021

Crowther R (2002) Space junk-protecting space for future generations. Science 296(5571):1241-1242. https://doi.org/10.1126/ science. 1069725

Dallas JA, Raval S, Gaitan JPA et al (2020) The environmental impact of emissions from space launches: a comprehensive review. J Clean Prod 255:120209. https://doi.org/10.1016/j.jclepro.2020. 120209

Dekorsy T, Humbert L, Hampf D et al (2017) Space debris—a problem with an optical solution. In: DINAMO 2017. https:/elib.dlr.de/ 112500/1/abstract\%20dekorsy\%20dinamo\%202017\%20final.pdf. Accessed 25 Dec 2021

Derrick H (2010) Scientists baffled by unusual upper atmosphere shrinkage. Cable News Network (CNN). http://edition.cnn.com/ 2010/US/07/16/nasa.upper.atmosphere.shrinking/index.html. Accessed 25 Dec 2021

DiaNuke (2020) Cosmos 954: the nuclear-powered satellite that fell from space. https://www.dianuke.org/cosmos-954-nuclear-power ed-satellite-that-fell-from-space/. Accessed 25 Dec 2021

Forshawa JL, Agliettia GS, Fellowesa S et al (2020) The active space debris removal mission RemoveDebris. Part 1: from concept to launch. Acta Astronaut 168:293-309. https://doi.org/10.1016/j. actaastro.2019.09.002

Graham F (2021) Daily briefing: satellite light pollution is everywhere. Nature. https://doi.org/10.1038/d41586-021-00874-7

Kamenev AA, Murina TA, Nezhdanova SN et al (1997) Study of the dynamics of the reflective characteristics of space junk in the visible region from piloted spacecraft. J Opt Technol 64(10):975-977. https://ui.adsabs.harvard.edu/abs/1997JOptT..64..975K

Kocifaj M, Kundracik F, Barentine JC et al (2021) The proliferation of space objects is a rapidly increasing source of artificial night sky brightness. Mon Notices Royal Astron Soc 504(1):L40-L44. https://doi.org/10.1093/mnras1/slab030

Laštovička J, Akmaev RA, Beig G et al (2006) Global change in the upper atmosphere. Science 314(5803):1253-1254. https://doi.org/ $10.1126 /$ science. 1135134

Lawler A (2011) Academy panel urges greater focus on space junk. Science. https://www.sciencemag.org/news/2011/09/academy-panelurges-greater-focus-space-junk. Accessed 25 Dec 2021

Leifer R, Juzdan ZR, Kelly WR et al (1987) Detection of uranium from cosmos-1402 in the stratosphere. Science 238(4826):512-514. https://doi.org/10.1126/science.238.4826.512

Lemaître A (2019) Space debris: from LEO to GEO: satellite dynamics and space missions. Springer INdAM Ser 134:155-157. https:// doi.org/10.1007/978-3-030-20633-8_3
Levi R (2007) The orbital menace — space garbage. The future of things (TFOT). https://thefutureofthings.com/3926-the-orbital-menacespace-garbage/. Accessed 25 Dec 2021

Lonckheen Martin (LM) (2020) Space fence. https://www.lockheedma rtin.com/en-us/products/space-fence.html. Accessed 25 Dec 2021

Loomis L (2015) Air force turns a keen eye on space junk. Science 347(6218):115. https://doi.org/10.1126/science.347.6218.115

Malik T (2021) Virgin Galactic's SpaceShipTwo Unity 22 launch with Richard Branson. See video and photos of the flight. Space. https://www.space.com/virgin-galactic-richard-branson-unity-22launch-explained. Accessed 25 Dec 2021

Marais E (2021) Space tourism: rockets emit 100 times more $\mathrm{CO}_{2}$ per passenger than flights-imagine a whole industry. https://www. space.com/space-tourism-rockets-emit-100-times-more-co2. Accessed 25 Dec 2021

Messier D (2021) Russia switches to year-long space station missions, doubles up on tourist flights as NASA gravy train ends. http:// parabolicarc.com/2021/07/19/russia-switches-to-year-long-spacestation-missions-doubles-up-on-tourist-flights-as-nasa-gravytrain-ends/. Accessed 25 Dec 2021

Microsoft News (MSN) (2021) ISS just had to swerve out of the way of space junk left over from 1994. https://www.msn.com/en-us/news/ technology/iss-just-had-to-swerve-out-of-the-way-of-space-junkleft-over-from-1994/ar-AARrKIl. Accessed 25 Dec 2021

Mizokami K (2020) The U.S. space force is ready to turn on its all-seeing 'Space Fence'. https://www.popularmechanics.com/military/ weapons/a30798053/us-space-force-space-fence/\#: :text=The\% 20U.S.\%20Space\%20Force\%20is\%20finally\%20ready\%20to,preve nt $\% 20$ collisions $\% 20$ and $\% 20$ monitor\%20the $\% 20$ satellites $\% 20$ of $\%$ 20adversaries. Accessed 25 Dec 2021

National Aeronautics and Space Administration (NASA) (2010) What is orbital debris? https://www.nasa.gov/audience/forstudents/5-8/ features/nasa-knows/what-is-orbital-debris-58.html. Accessed 25 Dec 2021

National Aeronautics and Space Administration (NASA) (2011) Frequently asked questions: orbital debris. https://www.nasa.gov/ news/debris_faq.html. Accessed 25 Dec 2021

National Aeronautics and Space Administration (NASA) (2020) Risks from orbital debris and space situational awareness. https://ntrs. nasa.gov/api/citations/20200000450/downloads/20200000450. pdf. Accessed 25 Dec 2021

National Aeronautics and Space Administration (NASA) (2021a) NASA teams delay spacewalk after debris notification. https:// blogs.nasa.gov/spacestation/2021a/11/30/nasa-teams-delay-space walk-after-debris-notification/. Accessed 25 Dec 2021a

National Aeronautics and Space Administration (NASA) (2021b) Space debris and human spacecraft. https://www.nasa.gov/missi on_pages/station/news/orbital_debris.html. Accessed 25 Dec 2021b

National Aeronautics and Space Administration (NASA) (2021c) NASA's perseverance rover begins its first science campaign on Mars. https://www.nasa.gov/feature/jpl/nasa-s-perseverancerover-begins-its-first-science-campaign-on-mars. Accessed 25 Dec 2021c

National Geographic (NG) (2019) Space junk is a huge problem-and it's only getting bigger. Space junk is a huge problem-and it's only getting bigger I National Geographic. Accessed 25 Dec 2021

National Public Radio (NPR) (2019) Cleaning up space junk. https:// www.npr.org/2019/12/13/787720682/cleaning-up-space-junk. Accessed 25 Dec 2021

Normile D (2016) Japan's damaged x-ray satellite: space scientists looking for clues. Science. https://doi.org/10.1126/science.aaf40 74 
Paddy V (1983) Russian satellite roulette. https://macleansarchive. azurewebsites.net/article/1983/1/24/russian-satellite-roulette. Accessed 25 Dec 2021

Physics Today (2009) Opinion: what is the impact of space debris on the Earth's atmosphere? https://doi.org/10.1063/PT.5.023358

Pultarova T (2018) High-tech harpoon could help clean up space junk. Space.com. https://www.space.com/40051-space-junk-harpoontest-success.html. Accessed 25 Dec 2021

Reeve D (2021) Space travel: the final frontier in luxury family vacations? https://familydestinationsguide.com/space-travel-familyvacations/. Accessed 25 Dec 2021

Rich V (1978) The facts about Kosmos-954. Nature 271:497-498. https://doi.org/10.1038/271497c0

Rich V (1983) Cosmos 1402 safe. Nature 301:458. https://doi.org/10. 1038/301458b0

Schaper EV (1999) UN call for action to clear up space junk. Nature 400:490. https://doi.org/10.1038/22833

Sheetz M (2019) Super fast travel using outer space could be $\$ 20$ billion market, disrupting airlines, UBS predicts. CNBC. https:// www.cnbc.com/2019/03/18/ubs-space-travel-and-space-touri sm-a-23-billion-business-in-a-decade.html. Accessed 25 Dec 2021

Sokol J (2021) Study finds nowhere on earth is safe from satellite light pollution. Science. https://doi.org/10.1126/science.abi6892

Space (2021) Yuri Gagarin, first man in space (photo gallery). https:// www.space.com/11346-photos-yuri-gagarin-vostok1-humanspaceflight.html. Accessed 25 Dec 2021

Space Law (SL) (1981) Settlement of claim between Canada and the Union of Soviet Socialist Republics for damage caused by 'Cosmos 954'. https://www.jaxa.jp/library/space_law/chapter_3/3-22-1_e.html. Accessed 25 Dec 2021

Spacex24 (2021) The future of space tourism. https://www.spacex24. com/2021/04/16/the-future-of-space-tourism/. Accessed 25 Dec 2021

Staughton J (2020) How does space debris impact earth's environment and atmosphere. Science ABC. https://www.scienceabc. com/nature/universe/how-does-space-debris-impact-earths-envir onment-and-atmosphere.html. Accessed 25 Dec 2021
Stein V (2021) Inspiration4: the first all-civilian spaceflight on SpaceX Dragon. Space. https://www.space.com/inspiration4-spacex.html. Accessed 25 Dec 2021

The European Space Agency (ESA) (2015) Mitigating space debris generation. http://www.esa.int/Safety_Security/Space_Debris/ Mitigating_space_debris_generation. Accessed 25 Dec 2021

The European Space Agency (ESA) (2019) ESA commissions world's first space debris removal. https://www.esa.int/Safety_Security/ Clean_Space/ESA_commissions_world_s_first_space_debris_ removal. Accessed 25 Dec 2021

The European Space Agency (ESA) (2020) About space debris. https:// www.esa.int/Safety_Security/Space_Debris/About_space_debris. Accessed 25 Dec 2021

United Arab Emirates Space Agency (UAESA) (2021) About EMM. https://emiratesmarsmission.ae/. Accessed 25 Dec 2021

Virgin Galactic (VG) (2021) Virgin Galactic successfully completes first fully crewed spaceflight. https://www.virgingalactic.com/ articles/virgin-galactic-successfully-completes-first-fully-crewedspaceflight/. Accessed 25 Dec 2021

Wall M (2011) First space tourist: how a U.S. millionaire bought a ticket to orbit https://www.space.com/11492-space-tourism-pione er-dennis-tito.html. Accessed 25 Dec 2021

Wen Q, Yang LW, Zhao SH et al (2018) Impacts of orbital elements of space-based laser station on small scale space debris removal. Optik 154:83-92. https://doi.org/10.1016/j.ijleo.2017.10.008

Witze A (2018) The quest to conquer earth's space junk problem. Nature 561(7721):24-26. https://doi.org/10.1038/ d41586-018-06170-1

World Information Service on Energy (WISE) (2005) Radioactive space debris: what goes up, must come down. https://www.wisei nternational.org/nuclear-monitor/629/radioactive-space-debriswhat-goes-must-come-down. Accessed 25 Dec 2021

Publisher's Note Springer Nature remains neutral with regard to jurisdictional claims in published maps and institutional affiliations. 